\title{
Hippocampal Subfields Volume Reduction in High Schoolers with Previous Verbal Abuse Experiences
}

\author{
Sang Won Lee ${ }^{1,2}$, Jae Hyun Yoo ${ }^{1}$, Ko Woon Kim ${ }^{1}$, Dongchan Kim ${ }^{3}$, HyunWook Park ${ }^{3}$, Jeewook Choi ${ }^{4}$, \\ Martin H. Teicher ${ }^{5,6}$, Bumseok Jeong ${ }^{1,7}$ \\ ${ }^{1}$ Computational Affective Neuroscience and Development Laboratory, Graduate School of Medical Science and Engineering, Korea Advanced \\ Institute of Science and Technology (KAIST), Daejeon, ${ }^{2}$ Department of Psychiatry, Kyungpook National University School of Medicine, Daegu, \\ ${ }^{3}$ Department of Electrical Engineering, KAIST, Daejeon, ${ }^{4}$ Department of Psychiatry, Daejeon St. Mary's Hospital, College of Medicine, The \\ Catholic University of Korea, Daejeon, Korea, ${ }^{5}$ Department of Psychiatry, Harvard Medical School, Boston, MA, ${ }^{6}$ Developmental Biopsychiatry \\ Research Program, McLean Hospital, Belmont, MA, USA, ${ }^{7}$ KAIST Institute for Health Science and Technology, KAIST, Daejeon, Korea
}

\begin{abstract}
Objective: Reduced hippocampal volume and alterations in white matter tracts have been frequently reported in adults having the history of emotional maltreatment. We investigated whether these structural change occur in adolescents with previous verbal abuse (VA) experiences.

Methods: Hippocampal subfield volume and white matter structural connectivity measures were assessed in 31 first year male high school students with various degrees of exposure to parental and peer VA.

Results: The high VA group showed significant volume reduction in the left cornu ammonis (CA) 1 and left subiculum compared to the low VA group $(p<0.05)$. Volumes of left hippocampal subfields CA1 and subiculum were negatively correlated with previous VA experiences $(p<0.05)$. Increased mean diffusivity (MD) of the splenium of the corpus callosum was related to high VA score across all subjects $(p<0.05)$. There was an inverse relationship between volume of the CA1 and subiculum and MD of the splenium $(p<0.05)$.

Conclusion: Exposure to parental and peer VA may affect development of the left hippocampal subfields and the splenium of corpus callosum. These structural alterations can be discernible during adolescence.
\end{abstract}

KEY WORDS: Hippocampus; Diffusion tensor imaging; Parenting; Adolescent.

\section{INTRODUCTION}

Childhood maltreatment is a major risk factor for behavioral problems and psychiatric disorders. ${ }^{1,2)}$ Previous studies make efforts to find structural changes of brain in the victims of childhood maltreatment. Among various structural changes, diminished hippocampal volume has been frequently reported in studies of adults with childhood maltreatment history. ${ }^{3-8)}$ Psychopathology related to childhood maltreatment, such as post-traumatic stress disorder, can inhibit the development of hippocampus. ${ }^{9,10)}$ However, while some studies have reported hippocampal

Received: November 15, 2016/Revised: January 31, 2017 Accepted: February 28, 2017

Address for correspondence: Bumseok Jeong, MD, PhD Graduate School of Medical Science and Engineering, Korea Advanced Institute of Science and Technology (KAIST), 291 Daehak-ro, Yuseong-gu, Daejeon 34141, Korea Tel: +82-42-350-4245, Fax: +82-42-350-7160 E-mail: bs.jeong@kaist.ac.kr volume reductions in maltreated children and adolescents, ${ }^{11-13)}$ many studies have not. ${ }^{14-19)}$

One reason why maltreatment-associated alterations in hippocampal volume have been reported more consistently in adults than children, is that early stress may have a delayed effect on hippocampal development. ${ }^{20,21)}$ Based on animal studies it is likely that robust effects of early life stress on hippocampal volume emerge between onset of puberty and early adulthood. ${ }^{20)}$ However, this needs to be determined in humans. Furthermore, most studies have not assessed volume of specific hippocampal subfields because methods for automated segmentation have recently been developed. ${ }^{22,23)}$ A recent study with young adults with verbal abuse (VA) experiences revealed that the specific hippocampal subfields, such as the left cornu ammonis (CA) 3, dentate gyrus (DG), and subiculum can be more vulnerable than the others. ${ }^{24)}$

In addition to hippocampal structure differences, sev-

(c) This is an Open-Access article distributed under the terms of the Creative Commons Attribution Non-Commercial License (http://creativecommons.org/licenses/by-nc/4.0) which permits unrestricted non-commercial use, distribution, and reproduction in any medium, provided the original work is properly cited. 
eral studies have reported abnormalities in white matter structural connectivity. In particular, diffusion tensor imaging (DTI) studies of maltreated individuals report diminished integrity in several white matter tracts including: uncinate fasciculus, ${ }^{25,26)}$ cingulum bundle, ${ }^{25-27)}$ corpus callosum, ${ }^{28,29)}$ fornix, ${ }^{25,27)}$ superior longitudinal fasciculus ${ }^{26,27,30)}$ and inferior longitudinal fasciculus. ${ }^{31)}$ Although several major fibers, such as cingulum bundle and fornix, connect hippocampus with other brain structures, ${ }^{32)}$ the lack of studies explores the relationship of hippocampal alteration with the change in the integrity of the fiber tract. Furthermore, while major white matter tracts are matured during adolescence, ${ }^{33,34)}$ most of those studies focused on children $^{25,29)}$ or adult subjects. ${ }^{22-24,27)}$ Therefore, alteration in white matter structural connectivity and its relationship with the development of hippocampus are needed to be verified in adolescents with childhood maltreatment experiences.

One of the major aims of the current study was to determine whether exposure to parental and peer VA were associated with diminished hippocampal subfield volume measures in adolescents. We evaluated effects of parent and peer verbal aggression on hippocampal subfields volume in first year high school students as they are likely at a stage of maturity when maltreatment related volume differences may become apparent. Further, they have recently passed through a developmentally sensitive period (11-13 years) when the hippocampus may be particularly susceptible. ${ }^{35)}$ Additionally, white matter structural connectivities were measured so as to determine if maltreatment related differences in subfield volume correlated with alteration in the integrity of specific fiber pathways. We expected that volume reduction in the specific hippocampal subfields and alterations in white matter tracts that may connect hippocampus with other brain regions become clear in adolescents.

\section{METHODS}

\section{Subjects}

To recruit preclinical subjects, we advertised our study as an investigation of language use in Korean adolescents to high school students (1st year). We explained detailed information about our study to the students who want to attend this study. Forty-three high school (1st year) male subjects agreed to participate in this study. Two psycholo- gists interviewed with participants using the KiddieSchedule for Affective Disorders and SchizophreniaPresent and Lifetime version-Korean version (KSADS-PL-K) and Wechsler Intelligence Scale for Children-Revised to evaluate the subjects' psychiatric history and intelligence quotient (IQ), respectively. Three authors in this study (one child psychiatrist and two psychiatrists) reviewed the results of KSADS-PL-K of participants to exclude participants with psychiatric disorders. Also, subjects who reported overt sexual or physical abuse experiences were excluded in our study. We thought considering all types of abuse can be confounding factors in a small sample study since effects of abuse experiences varies depending on the types of abuse. ${ }^{32)}$

Exposure to parent or peer VA was assessed using the Korean version of the Verbal Abuse Questionnaire (VAQ). ${ }^{36)}$ A score of 40 or above on the $V A Q$ was defined as substantial exposure for peer $V A^{28)}$ and high-level exposure for parental $V A^{27)}$ in previous studies. This cutoff point was verified in our previous validation study of the Korean version of the VAQ with 5,814 young adults. ${ }^{36)}$ Symptoms of anxiety and depression were evaluated using the State-Trait Anxiety Inventory (STAI) ${ }^{37)}$ and Beck Depression Inventory (BDI). ${ }^{38)}$

Exclusion criteria of the study were previous/current psychiatric history or sexual/physical abuse history, full-scale IQ less than 70, significant head trauma or brain disease history, or any contraindication for functional magnetic resonance imaging ( $\mathrm{fMRI}$ ). Of the 43 subjects, twelve subjects were excluded based on the pre-established criteria: seven subjects with low IQs $(<70)$, two subjects with a history of a major depressive disorder, one subject who reported a previous traffic accident, one sub-

Table 1. Characteristics of the subjects

\begin{tabular}{lc}
\multicolumn{1}{c}{ Characteristic } & Data \\
\hline Age (yr) & $16.12 \pm 0.48$ \\
Intelligence quotient & $101.42 \pm 17.41$ \\
Total VAQ & $65.94 \pm 25.27$ \\
Peer VAQ & $37.77 \pm 18.07$ \\
Parental VAQ & $28.16 \pm 10.92$ \\
Beck Depression Inventory & $5.06 \pm 4.32$ \\
State-Trait Anxiety Inventory-State & $40.35 \pm 7.67$ \\
State-Trait Anxiety Inventory-Trait & $46.55 \pm 6.61$ \\
\hline
\end{tabular}

Values are presented as mean \pm standard deviation.

VAQ, Verbal Abuse Questionnaire score. 
ject with a craniopharyngioma (suspicious) in the nasal cavity, and one subject who reported severe VA history (VAQ score $>3$ standard deviation [SD]). Finally, 31 subjects (mean age, 16.12; SD, 0.48) were used for statistical analysis. All of the 31 subjects represented no previous/current psychiatric history including depressive disorder, anxiety disorder, psychotic disorder and substance abuse in KSADS-PL-K. Characteristics of the subjects were described in Table 1.

For group comparisons, subjects were divided into low VA $(n=15)$ and high VA $(n=16)$ groups, based on the scores of peer and parental VAQ using k-means clustering analysis. This data-driven classification method created a low VA group in which no subject had substantial exposure to either peer or parental VA (Fig. 1). As expected, mean scores in the low $V A$ group (peer $V A Q, 22.4$; parental $V A Q, 21.5)$ were significantly lower than in the high VA group (peer VAQ, 52.2; parental VAQ, 34.4) (all $p<$ 0.01).

All subjects and their parents voluntarily joined this study with written consent. The study was approved by the Ethics Committee of Korea Advanced Institute of Technology (KAIST; KH2012-27).

\section{Image Acquisition}

All MRI images were acquired at 3.0 Tesla (MAGNETOM ${ }^{R}$ Verio; Siemens, Erlangen, Germany). A high resolution structural image was obtained with a T1 weighed sequence $(\mathrm{Tl}=900 \mathrm{~ms}, \mathrm{TR}=1800 \mathrm{~ms}, \mathrm{TE}=2.52 \mathrm{~ms}$, flip angle $=9^{\circ}, \mathrm{FOV}=256 \times 256 \mathrm{~mm}$, slice thickness $=1 \mathrm{~mm}$, voxel

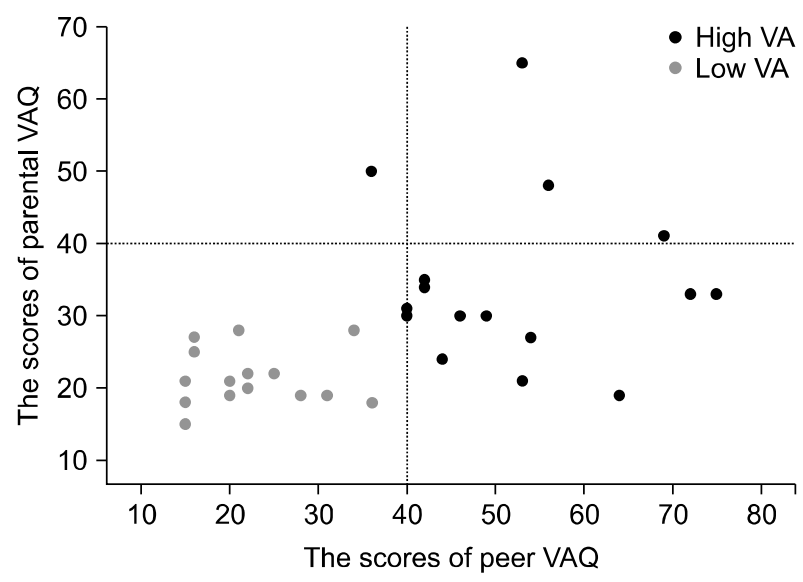

Fig. 1. Scatterplot of the Verbal Abuse Questionnaire (VAQ) scores in the subjects. The dashed line represents the cutoff point 40 of the VAQ. size $=1 \times 1 \times 1 \mathrm{~mm}$ ). A DTI was also acquired with 64 encoding directions and the following parameters: $b=1,000$ $\mathrm{s} / \mathrm{mm}^{2}, \mathrm{TR}=9,700 \mathrm{~ms}, \mathrm{TE}=93 \mathrm{~ms}, \mathrm{FOV}=230 \times 230 \mathrm{~mm}$, slice thickness $=2.5 \mathrm{~mm}$, voxel size $=1.8 \times 1.8 \times 2.5 \mathrm{~mm}$. In addition, our subjects also finished task-based fMRI scan, and the results of fMRI are recently published. ${ }^{39)}$

\section{The Analyses of Hippocampal Subfields}

Both automated cortical parcellation and volumetric segmentation were performed using Freesurfer software version 5.3.0 (http://freesurfer.net), while the hippocampus was analyzed using recently improved segmentation procedures now included in version $6 .{ }^{23)}$

Overall, the segmentation process consisted of two steps; extraction of the cortical surface and modeling of the cortical surface. ${ }^{40-44)}$ In the cortical extraction step, motion correction, automated Talairach transformation, skull stripping, segmentation of the subcortical structures and intensity normalization were included. In the cortical modeling step, tessellation of the gray-white matter boundary using segmented white matter, automated topology correction, and surface deformation for placing the surface within the optimal boundary. After the cortical models were made, cortical thickness using Euclidean distance between vertices and cortical volume was measured. The volumes of thirteen hippocampus subfields including the CA1, CA3, CA4, DG, and subiculum were automatically segmented using Bayesian inference based on the computation atlas that combines in vivo and ultra-high resolution ex vivo MRIs images. ${ }^{23)}$ An estimated total intracranial volume (eTIV) was also acquired to control the effects of variation of head sizes.

Partial correlation analysis was used to evaluate the relationships between the volumes and VA experiences using the scores of total $V A Q$, peer $V A Q$, and parental $V A Q$. In addition, analysis of covariance (ANCOVA) was used to determine if there were group differences in thickness and hippocampal subfield volumes. Age, total IQ, and eTIV were included as covariates, and $p$ value less than 0.05 represented statistical significance in these analyses.

\section{The Analyses of White Matter Connectivity Using Tract-based Spatial Statistics (TBSS)}

One subject who was in the low VA group was excluded in the DTI analysis due to poor cooperation. The DTI was processed using FMRIB's Diffusion Toolbox in 
FMRIB Software Library v5.0. After correcting for eddy current distortions and head motion, fractional anisotropy

Table 2. The results of partial correlation analysis between VAQ score and hippocampal subfields

\begin{tabular}{llrl}
\hline \multicolumn{1}{c}{ Measure } & PeVAQ & PaVAQ & ToVAQ \\
\hline Right CA1 & -0.192 & -0.084 & -0.171 \\
Right CA3 & -0.141 & -0.242 & -0.201 \\
Right CA4 & -0.087 & -0.127 & -0.115 \\
Right DG & -0.115 & -0.140 & -0.140 \\
Right subiculum & -0.120 & 0.005 & -0.083 \\
Right total & -0.242 & -0.175 & -0.245 \\
Left CA1 & $-0.445^{\dagger}$ & -0.341 & $-0.458^{\dagger}$ \\
Left CA3 & $-0.326^{*}$ & -0.214 & $-0.321^{*}$ \\
Left CA4 & $-0.342^{*}$ & -0.207 & $-0.329^{*}$ \\
Left DG & $-0.355^{*}$ & -0.189 & $-0.331^{*}$ \\
Left subiculum & $-0.385^{\dagger}$ & -0.271 & $-0.386^{\dagger}$ \\
Left total & $-0.467^{\dagger}$ & -0.306 & $-0.459^{\dagger}$ \\
\hline
\end{tabular}

VAQ, Verbal Abuse Questionnaire; CA, cornu ammonis; DG, dentate gyrus; PeVAQ, peer VAQ score; PaVAQ, parental VAQ score; ToVAQ, sum of peer and parental VAQ scores. ${ }^{*} p<0.1,{ }^{\dagger} p<0.05$.
(FA), radial diffusivity (RD), axial diffusivity (AD) and mean diffusivity $(\mathrm{MD})$ of each voxel was measured using a diffusion tensor model. A mode of anisotropy ( $\mathrm{MO}$ ) was used to provide complimentary information related to tract anisotropy, such as crossing or kissing fiber. ${ }^{45)}$ Using TBSS pipeline, ${ }^{46)}$ FA maps in each subject space were projected into the $1 \times 1 \times 1 \mathrm{~mm}^{3}$ MNI152 space. A skeletonized FA image was created with a mean FA image in each subject. All FA images were projected onto the mean FA skeleton and were thresholded using an FA value of 0.2 to reduce inter-subject variability. Other diffusion metrics images were projected onto the skeleton using a transformation matrix for FA map. The skeletonized maps consisting of $F A, M D, A D, M D$, and $M O$ were used to assess the group differences and correlation with the VAQs (peer VAQ, parental VAQ, and total VAQ). In the group analyses, non-parametric multiple comparison correction was performed with 10,000 random permutations and a two-dimensional threshold-free cluster enhancement option were used. The threshold for statistical significance
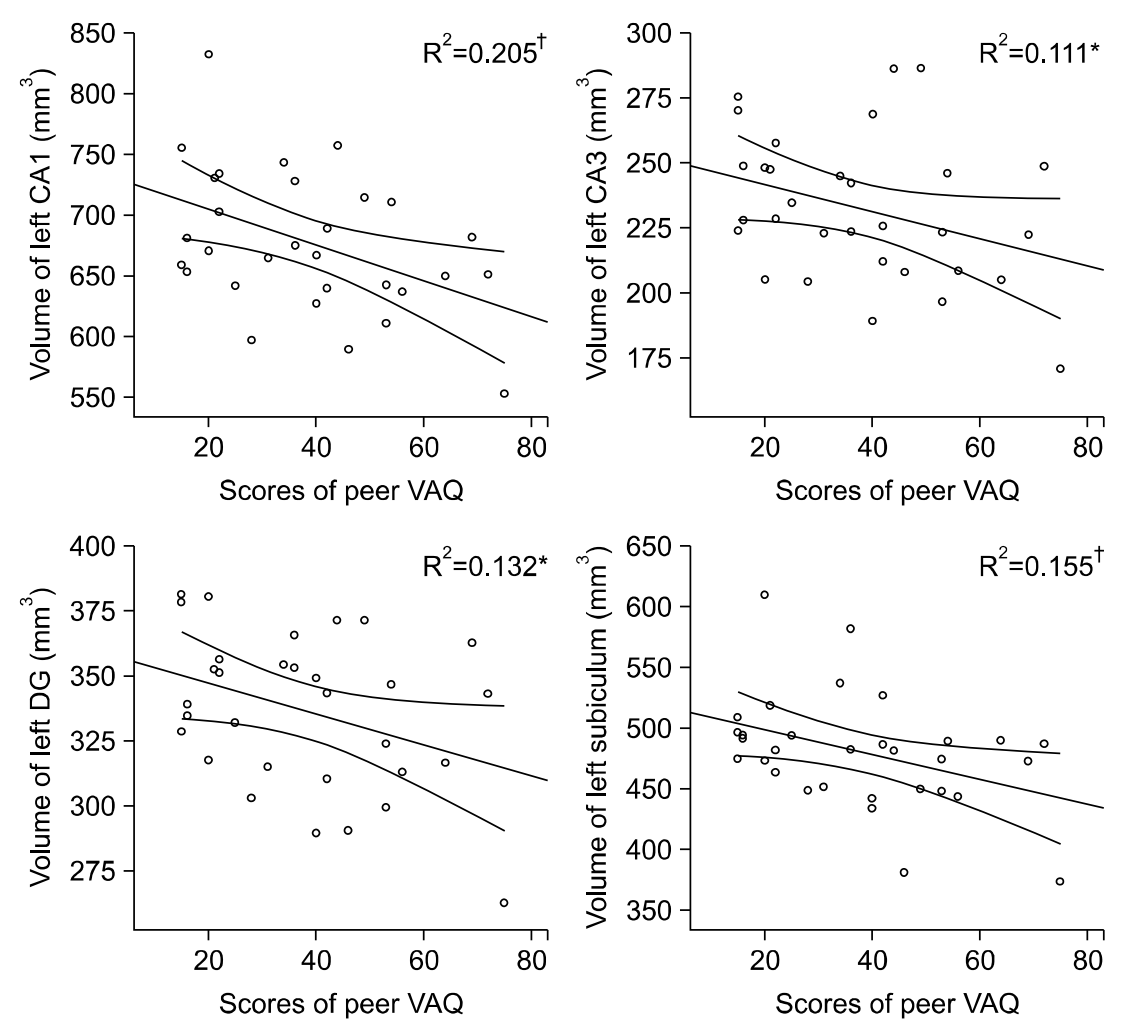
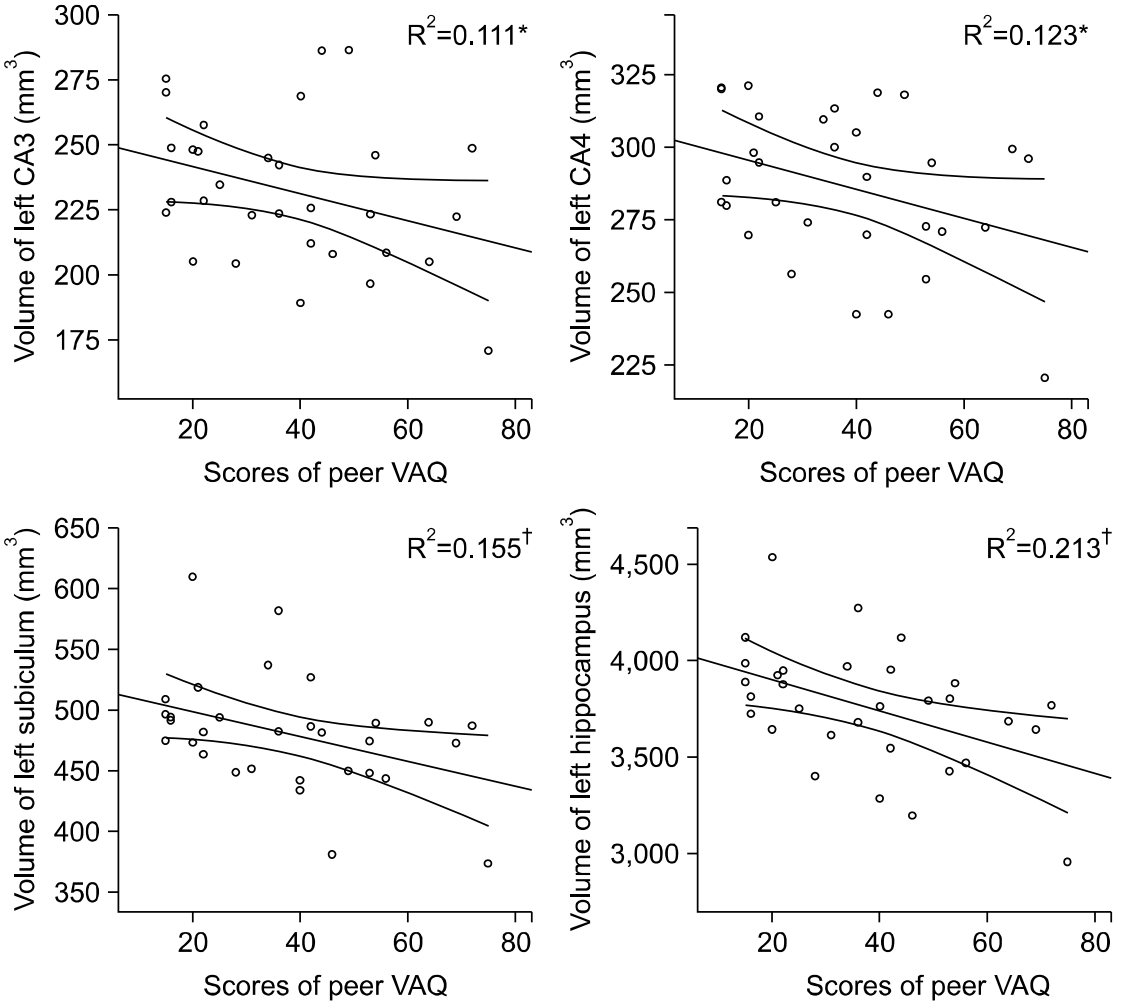

Fig. 2. Regression graph showed relationships between the volumes of left hippocampal subfields and peer Verbal Abuse Questionnaire (VAQ) scores.

CA, cornu ammonis; DG, dentate gyrus.

${ }^{*} p<0.1,{ }^{\dagger} p<0.05$ (in partial correlation analysis). 
was a corrected $p<0.05$. Age and total IQ were used as covariates. TrackVis (version 0.6.0.1), which is available at http://www.trackvis.org, was used for streamline tractography.

\section{RESULTS}

Relationships between the Volumes of Hippocampal Subfields and Previous Verbal Abuse Experiences

In partial correlation analysis, previous VA experiences were significantly correlated with the volumes of the left CA1 $(r=-0.458, p=0.014$ for total VAQ; $r=-0.445, p=$

Table 3. Group differences of hippocampal subfields

\begin{tabular}{|c|c|c|c|c|}
\hline Measure $\left(\mathrm{mm}^{3}\right)$ & Low VA $(n=15)$ & High VA $(n=16)$ & Analysis, $F(1,26)$ & Effect size, PES \\
\hline Right CA1 & $756.8 \pm 89.5$ & $728.4 \pm 79.3$ & 0.59 & 0.02 \\
\hline Right CA3 & $250.2 \pm 33.5$ & $241.5 \pm 42.0$ & 0.03 & 0.01 \\
\hline Right CA4 & $301.6 \pm 31.2$ & $294.2 \pm 36.5$ & 0.14 & 0.01 \\
\hline Right DG & $354.6 \pm 35.4$ & $344.6 \pm 39.9$ & 0.25 & 0.01 \\
\hline Right fimbria & $106.2 \pm 10.4$ & $105.9 \pm 19.2$ & $<0.01$ & $<0.01$ \\
\hline Right subiculum & $494.7 \pm 43.3$ & $482.8 \pm 47.5$ & 0.13 & 0.01 \\
\hline Right presubiculum & $335.1 \pm 38.8$ & $327.4 \pm 43.3$ & 0.04 & $<0.01$ \\
\hline Right total & $4,011.0 \pm 346.2$ & $3,846.8 \pm 364.7$ & 1.12 & 0.04 \\
\hline Left CA1 & $703.3 \pm 59.1$ & $656.0 \pm 50.2$ & $4.27^{*}$ & 0.14 \\
\hline Left CA3 & $238.8 \pm 20.7$ & $226.3 \pm 33.3$ & 0.92 & 0.03 \\
\hline Left CA4 & $294.5 \pm 20.7$ & $279.2 \pm 28.6$ & 1.81 & 0.07 \\
\hline Left DG & $346.0 \pm 24.5$ & $327.9 \pm 32.2$ & 2.06 & 0.07 \\
\hline Left fimbria & $113.9 \pm 17.3$ & $109.8 \pm 20.4$ & 0.02 & $<0.01$ \\
\hline Left subiculum & $501.7 \pm 45.4$ & $460.1 \pm 40.3$ & $5.45^{*}$ & 0.17 \\
\hline Left presubuculum & $339.1 \pm 29.0$ & $320.8 \pm 34.9$ & 1.79 & 0.06 \\
\hline Left total & $3,899.2 \pm 275.6$ & $3,624.4 \pm 299.1$ & $5.30^{*}$ & 0.17 \\
\hline
\end{tabular}

Values are presented as mean \pm standard deviation.

VA, verval abuse; PES, partial eta squared; CA, cornu ammonis; DG, dentate gyrus.

$* p<0.05$.

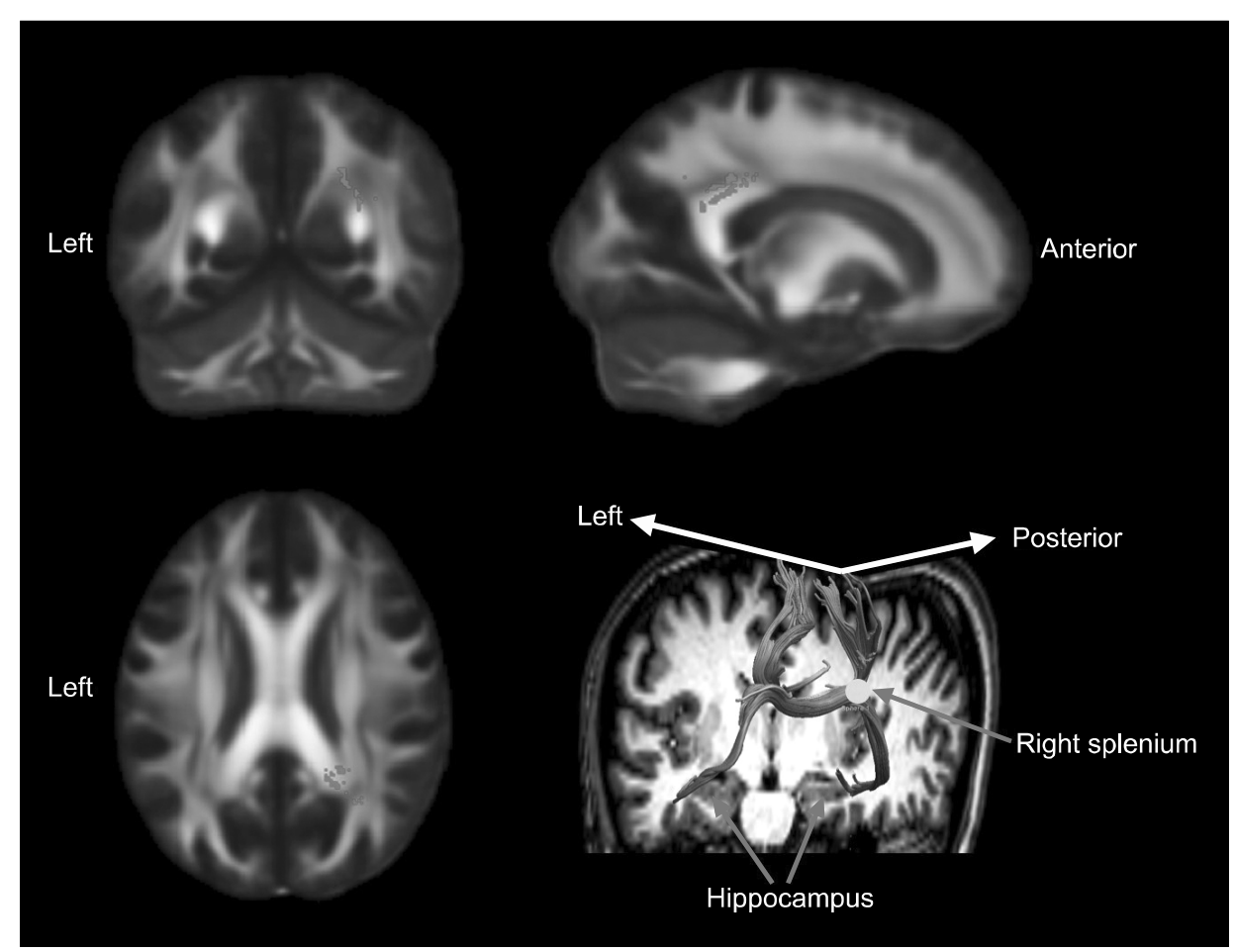

Fig. 3. The white matter region that showed a positive correlation with total Verbal Abuse Questionnaire (VAQ) scores. The mean diffusivity of splenium of corpus callosum and right posterior corona radiata showed a significant positive relationship with total VAQ scores (corrected $\quad p<0.05$ ). Montreal Neurological Institute (MNI) coordinates were $X=28, Y=-55, Z=23$. The background images are MNI152 templates. 
0.018 for peer $\mathrm{VAQ})$ and subiculum $(r=-0.386, p=0.043$ for total VAQ; $r=-0.385, p=0.043$ for peer VAQ) (Table 2). Also, other left hippocampal subfields (CA1, CA3, CA4, and DG) showed marginally significant relationship with previous $\mathrm{VA}$ experiences (total $\mathrm{VAQ}$ and peer $\mathrm{VAQ}$ ) (all $p<0.1$ ) (Table 2, Fig. 2). The scores of behavioral measurements including BDI and STAI scores did not show any significant correlation result with the volumes of hippocampal subfields.

In two group comparison analysis using ANCOVA, the high VA group showed significant volume reduction in the left CA1 and left subiculum compared to the low VA group (Table 3).

\section{Relationships between the White Matter Connectivity and Previous Verbal Abuse Experiences}

There was a significant positive correlation between $\mathrm{MD}$ in the splenium of the corpus callosum overlying the right corona radiata with total VAQ scores (corrected $p<$ 0.05; Fig. 3). There were no other significant correlations with other measures of diffusivity and no significant group difference was found in FA, RD, AD, MD, and $M O$ values between the high and low VA groups. Also, the scores of behavioral measurements including BDI and STAI scores did not show any significant correlation result with the measurements of white matter connectivity.

\section{Relationship between Volume of Hippocampal Subfields and MD in the Region of the Splenium of the Corpus Callosum}

$\mathrm{MD}$ values were extracted from the region of interest (ROI) within the splenium of the corpus callosum (voxel size $=11$, corrected $p<0.04$ ) and showed high degree of significance in the correlation analysis with the volume of hippocampal subfields. Across all subjects, MD values in the ROI showed significant negative relationships with volumes of the left CA1 $(r=-0.481, p=0.011)$, left CA4 ( $r=-0.424, p=0.027)$, left DG $(r=-0.387, p=0.046)$, and left subiculum $(r=-0.420, p=0.029)$. Streamline tracts generated from the $\mathrm{ROI}$ within the splenium reached bilateral hippocampus (Fig. 3).

\section{DISCUSSION}

In our results, first year high school students who reported high levels of exposure to VA had smaller volumes of the left CA1 and subiculum compared to students who reported low levels of exposure to VA. Furthermore, white matter changes involving the splenium of the corpus callosum revealed significant relationships with VA experiences and with hippocampal subfield reduction.

The volume of human hippocampus increases through adolescence. ${ }^{47)}$ The hippocampus has a high density of corticosteroid and corticotropin-releasing hormore $(\mathrm{CRH})$ receptors, and exposure to early life chronic stress, which induces the release of $\mathrm{CRH}$ and corticosteroid, is associated with the structural atrophy of hippocampus. $^{48-50)}$ In line with previous studies, ${ }^{3,4,24,51)}$ only left hippocampal subfields volume showed significant negative correlations with VA experiences in our study. Left hippocampus is particularly involved in autobiographical event memory processing. ${ }^{52)}$ Childhood maltreatment experiences can influence more on left than right hippocampus. Also, the deleterious effects of stress hormones, such as corticosteroid, on hippocampus occurs through excitatory pathway mediated by $\mathrm{N}$-methyl-D-aspartate (NMDA) receptors. ${ }^{53)}$ Differential distribution of NMDA receptor subunits between the left and right sides hippocampus is reported, ${ }^{54)}$ and lateralization of stress-susceptibility can be aroused by asymmetrical distributions of NMDA receptors between the left and right hippocampus. ${ }^{55)}$ Furthermore, it is unclear why the left CA1 and subiculum appeared to be more significantly associated with degree of exposure to VA than other subfields, but some previous studies lend credence to this observation. First, previous studies have reported that the CA1 subfield is more vulnerable to corticosterone administration, ${ }^{56)}$ metabolic insult, ${ }^{57)}$ and ischemic injury ${ }^{58,59)}$ than other hippocampal subfields. Second, chronic early life stress induces dendrite atrophy in the CA1 pyramidal neuron. ${ }^{50,60)}$ Third, the density of glutamatergic receptor (NMDA) is higher in the CA1 than in the CA3 and DG. ${ }^{61)}$ Chronic stress can increase glutamatergic transmission that can be associated with a metabolic vulnerability. ${ }^{62)}$ In addition, the subiculum subfield seems to be closely connected to the stress system and involved in glucocorticoid negative feedback. ${ }^{63,64)}$ The subiculum has abundant glucocorticoid receptors; ${ }^{65,66)}$ several studies reported higher density of glucocorticoid receptor in subiculum than in other hippocampal subfields, such as the CA3, CA4, ${ }^{67)}$ and DG. ${ }^{68)}$ Therefore, the changes in the CA1 and subiculum could be sensitive markers in the victims of VA. 
Other left hippocampal subfields including the CA3 and DG also showed marginally significant relationships with previous VA experiences in this study. There are many studies that suggested susceptibility to chronic stress in other hippocampal subfields including the CA3 ${ }^{69)}$ In animal studies, single or repeated stress reduces brain-derived neurotrophic factor gene expression in the $\mathrm{CA} 3$ and $\mathrm{DG}^{70)}$; chronic stress suppress neurogenesis in the DG and remodeling of CA3 pyramidal cells. ${ }^{48,71,72)}$ In sum, volume reductions in left hippocampal subfields can be generally affected and both the CA1 and subiculum may be more susceptible to VA experiences in a dose-dependent pattern.

In a study of adults with maltreatment, the strongest associations with number of types of abuse and severity of abuse were found in the left CA2-3, CA4-DG, and subiculum. ${ }^{24)}$ Recently developed method for hippocampal subfields analysis provide a more accurate measure of the CA1 volume, ${ }^{73)}$ and reassign a significant portion of the CA2-CA3 to CA1. Therefore, our results on the left CA1 and subiculum volume reductions may be similar to the results of previous studies in adult ${ }^{8,24)}$ and pediatric participants. ${ }^{12)}$ One reason why we may have observed maltreatment associated differences in hippocampal volume in relatively young adolescents is that all of our participants were males. Prior reports suggest that the hippocampus appears to be much more vulnerable to effects of maltreatment in males than in females. ${ }^{74,75)}$

Multiple factors including genetic predisposition and environmental stressors affect the development of psychopathology. ${ }^{76)}$ Among multiple factors, small hippocampus can be a vulnerability factor for future psychiatric illnesses. In a recent large-scale study, small hippocampus volume is significantly related to major depressive disorder ${ }^{77)}$ as well as schizophrenia. ${ }^{78)}$ Also, subjects with small hippocampus volume are vulnerable to psychological trauma. ${ }^{79)}$ It is still unclear whether small volume of hippocampus results from the neurotoxic effects of psychiatric illnesses or represents a vulnerable factor for future psychiatric illnesses. In our study with healthy subjects, symptoms of depression and anxiety did not account for hippocampus volume reduction. Although additional study to confirm causality between hippocampus volume reduction and VA experiences, we suspect that small hippocampus volume related to VA experiences is an objective risk factor that makes the brain more vulner- able to psychiatric illnesses. Therefore, we suggest that adolescents with VA experiences and related volume reduction in the hippocampus are should be closely observed to prevent or detect future psychiatric illnesses.

While no significant group difference was reported in white matter connectivities, the MD of the splenium of the corpus callosum involving the right posterior corona radiata was positively related to the total VAQ scores. In studies of normal healthy people, 11-12 years of age is the starting point where the growth of the posterior part of the corpus callosum is dominant over the anterior part ${ }^{80}$; the $\mathrm{MD}$ of the splenium of the corpus callosum is lower in young adults than in children in the age range 9.4 to 11.5 years ${ }^{81)}$ or 8 to 12 years. ${ }^{82)}$ In a longitudinal DTI study, a large percentage of subjects in 15 to 22 years group had decreasing the MD in splenium of corpus callosum. ${ }^{83)}$ Therefore, the MD of the splenium may decrease throughout the period of mid to late teens in normal development, and decrement of MD seems to be related to maturation. Further, our results support previous studies that showed alterations of the splenium of the corpus callosum in victims of peer $\mathrm{VA}^{28)}$ and neglect. ${ }^{84)}$

It is unclear whether the changes in the hippocampal subfields and corpus callosum are associated or independent in our cross-sectional design. However, the hippocampal commissure is closely related to the splenium of the corpus callosum ${ }^{85)}$ and crosses the midline under the splenium. ${ }^{86)}$ In mouse studies, the hippocampal fissure is formed earlier than the splenium of the corpus callosum, and it seems to be mediated by a growth substrate. ${ }^{87,88)}$ In studies of early Alzheimer disease, which representatively affects hippocampal region alteration, abnormalities of the hippocampus and splenium of corpus callosum simultaneously occur ${ }^{89)}$ and represent a direct correlation when applying a permissive threshold. ${ }^{90)}$ Our correlation result also supports the relationship between the changes of the splenium and hippocampal subfields. However, the causality or trajectory of these changes should be investigated in future longitudinal studies.

Our study has several limitations. First, our results cannot be generalized to females because only male subjects were studied, and there appear to be significant gender differences in hippocampal susceptibility to maltreatment. ${ }^{7,74)}$ Second, due to the cross-sectional design, our results only explain current states that may vary with brain development and cannot confirm the effects of small hip- 
pocampus on future psychiatric illnesses. Also, it is possible that subjects with small hippocampus or altered anatomical connectivity may be vulnerable to abuse experiences. Our study cannot verify the causality among hippocampus volume, anatomical alteration, and VA experiences. Thus, a longitudinal design is needed to track the development of psychiatric illnesses and the changes in the volume of hippocampal subfields, white matter connectivity, and cortical structures. Third, although hippocampal volume findings were correlated with degree of exposure to VA, we cannot conclude that VA was the primary determinant as degree of exposure to other types of maltreatment were not quantified, and there are significant correlations between degree of exposure to peer and parental VA and other forms of maltreatment. ${ }^{91)}$ In particular, adolescents who experience peer VA have often been exposed to earlier abusive experiences, and peer victimization may mediate the association between early abuse and psychopathology. ${ }^{92)}$ Prior studies reporting significant associations between parent and peer VA and brain measures specifically eliminated subjects who were exposed to any other forms of maltreatment. ${ }^{24,27,93)}$ Fourth, although we set the cutoff score based on previous studies with young adults, ${ }^{27,28,36)}$ the cutoff score in VAQ of 40 is not regorously validated in adolescents. To compasate this limitation, cluster analysis was used to define high or low VA groups. In the aspect of the continuum of the VAQ score, we also conducted group comparison analysis as well as correlation (regression) analysis. Fifth, our small sample size could reduce explanatory power of our results.

In spite of the limitations, our results provide further support for maltreatment related effects on hippocampal development and show that they are discernible in male high school freshman. As the hippocampus plays an important role in formation and retrieval of memories this may have important implications for school performance. Members of our society need to put more effort into protecting our children, especially during developmentally sensitive periods, from emotional abuse in order to promote healthy hippocampal development.

\section{acknowledgments}

This research was supported by the Brain Research Program through the National Research Foundation of Korea (NRF) funded by the Ministry of Science, ICT \&
Future Planning (NRF-2016M3C7A1914448) and in part by grant for KAIST Future Systems Healthcare Project from the Ministry of Education, Science and Technology (N01130009, N01130010, G04110085), Student Mental Research Center Project through Korea Brain Research Institute funded by the Ministry of Science, ICT \& Future Planning (2231-415, KBRI-20130007).

\section{REFERENCES}

1. Green JG, McLaughlin KA, Berglund PA, Gruber MJ, Sampson NA, Zaslavsky AM, et al. Childhood adversities and adult psychiatric disorders in the national comorbidity survey replication I: associations with first onset of DSM-IV disorders. Arch Gen Psychiatry 2010;67:113-123.

2. Vachon DD, Krueger RF, Rogosch FA, Cicchetti D. Assessment of the harmful psychiatric and behavioral effects of different forms of child maltreatment. JAMA Psychiatry 2015; 72:1135-1142.

3. Bremner JD, Randall P, Vermetten E, Staib L, Bronen RA, Mazure $C$, et al. Magnetic resonance imaging-based measurement of hippocampal volume in posttraumatic stress disorder related to childhood physical and sexual abuse--a preliminary report. Biol Psychiatry 1997;41:23-32.

4. Vythilingam M, Heim C, Newport J, Miller AH, Anderson E, Bronen R, et al. Childhood trauma associated with smaller hippocampal volume in women with major depression. Am J Psychiatry 2002; 159:2072-2080.

5. Weniger G, Lange C, Sachsse U, Irle E. Reduced amygdala and hippocampus size in trauma-exposed women with borderline personality disorder and without posttraumatic stress disorder. J Psychiatry Neurosci 2009;34:383-388.

6. Dannlowski U, Stuhrmann A, Beutelmann V, Zwanzger P, Lenzen $\mathrm{T}$, Grotegerd D, et al. Limbic scars: long-term consequences of childhood maltreatment revealed by functional and structural magnetic resonance imaging. Biol Psychiatry 2012;71:286-293.

7. Samplin E, Ikuta T, Malhotra AK, Szeszko PR, Derosse P. Sex differences in resilience to childhood maltreatment: effects of trauma history on hippocampal volume, general cognition and subclinical psychosis in healthy adults. I Psychiatr Res 2013;47:1174-1179.

8. Van Dam NT, Rando K, Potenza MN, Tuit K, Sinha R. Childhood maltreatment, altered limbic neurobiology, and substance use relapse severity via trauma-specific reductions in limbic gray matter volume. JAMA Psychiatry 2014; 71:917-925.

9. Whittle S, Dennison M, Vijayakumar N, Simmons JG, Yücel $\mathrm{M}$, Lubman DI, et al. Childhood maltreatment and psychopathology affect brain development during adolescence. I Am Acad Child Adolesc Psychiatry 2013;52:940-952.e1.

10. Morey RA, Haswell CC, Hooper SR, De Bellis MD. Amygdala, hippocampus, and ventral medial prefrontal cortex volumes 
differ in maltreated youth with and without chronic posttraumatic stress disorder. Neuropsychopharmacology 2016;41: 791-801.

11. Edmiston EE, Wang F, Mazure CM, Guiney J, Sinha R, Mayes LC, et al. Corticostriatal-limbic gray matter morphology in adolescents with self-reported exposure to childhood maltreatment. Arch Pediatr Adolesc Med 2011;165:10691077.

12. Pagliaccio D, Luby JL, Bogdan R, Agrawal A, Gaffrey MS, Belden AC, et al. Stress-system genes and life stress predict cortisol levels and amygdala and hippocampal volumes in children. Neuropsychopharmacology 2014;39:1245-1253.

13. Rao U, Chen LA, Bidesi AS, Shad MU, Thomas MA, Hammen CL. Hippocampal changes associated with early-life adversity and vulnerability to depression. Biol Psychiatry 2010;67:357364.

14. Tupler LA, De Bellis MD. Segmented hippocampal volume in children and adolescents with posttraumatic stress disorder. Biol Psychiatry 2006; 59:523-529.

15. De Bellis MD, Keshavan MS, Shifflett H, lyengar S, Beers SR, Hall J, et al. Brain structures in pediatric maltreatment-related posttraumatic stress disorder: a sociodemographically matched study. Biol Psychiatry 2002;52:1066-1078.

16. Carrion VG, Weems CF, Watson C, Eliez S, Menon V, Reiss AL. Converging evidence for abnormalities of the prefrontal cortex and evaluation of midsagittal structures in pediatric posttraumatic stress disorder: an MRI study. Psychiatry Res 2009;172:226-234.

17. Lupien SJ, Parent S, Evans AC, Tremblay RE, Zelazo PD, Corbo $\mathrm{V}$, et al. Larger amygdala but no change in hippocampal volume in 10-year-old children exposed to maternal depressive symptomatology since birth. Proc Natl Acad Sci US A 2011;108:14324-14329.

18. Sheridan MA, Fox NA, Zeanah $\mathrm{CH}$, McLaughlin KA, Nelson CA 3rd. Variation in neural development as a result of exposure to institutionalization early in childhood. Proc Natl Acad Sci U S A 2012;109:12927-12932.

19. Woon FL, Hedges DW. Hippocampal and amygdala volumes in children and adults with childhood maltreatment-related posttraumatic stress disorder: a meta-analysis. Hippocampus 2008; 18:729-736.

20. Andersen SL, Teicher MH. Delayed effects of early stress on hippocampal development. Neuropsychopharmacology 2004:29:1988-1993.

21. Rao H, Betancourt L, Giannetta JM, Brodsky NL, Korczykowski M, Avants BB, et al. Early parental care is important for hippocampal maturation: evidence from brain morphology in humans. Neuroimage 2010;49:1144-1150.

22. Van Leemput $\mathrm{K}$, Bakkour A, Benner T, Wiggins G, Wald LL, Augustinack J, et al. Automated segmentation of hippocampal subfields from ultra-high resolution in vivo MRI. Hippocampus 2009;19:549-557.

23. Iglesias JE, Augustinack JC, Nguyen K, Player CM, Player A,
Wright M, et al. A computational atlas of the hippocampal formation using ex vivo, ultra-high resolution MRI: Application to adaptive segmentation of in vivo MRI. Neuroimage 2015; 115:117-137.

24. Teicher MH, Anderson CM, Polcari A. Childhood maltreatment is associated with reduced volume in the hippocampal subfields CA3, dentate gyrus, and subiculum. Proc Natl Acad SCi U S A 2012;109:E563-E572.

25. Eluvathingal TJ, Chugani HT, Behen ME, Juhász C, Muzik O, Maqbool M, et al. Abnormal brain connectivity in children after early severe socioemotional deprivation: a diffusion tensor imaging study. Pediatrics 2006;117:2093-2100.

26. Benedetti F, Bollettini I, Radaelli D, Poletti S, Locatelli C, Falini A, et al. Adverse childhood experiences influence white matter microstructure in patients with bipolar disorder. Psychol Med 2014;44:3069-3082.

27. Choi J, Jeong B, Rohan ML, Polcari AM, Teicher MH. Preliminary evidence for white matter tract abnormalities in young adults exposed to parental verbal abuse. Biol Psychiatry 2009;65:227-234.

28. Teicher MH, Samson JA, Sheu YS, Polcari A, McGreenery CE. Hurtful words: association of exposure to peer verbal abuse with elevated psychiatric symptom scores and corpus callosum abnormalities. Am J Psychiatry 2010;167:1464-1471.

29. Jackowski AP, Douglas-Palumberi $\mathrm{H}$, Jackowski M, Win L, Schultz RT, Staib LW, et al. Corpus callosum in maltreated children with posttraumatic stress disorder: a diffusion tensor imaging study. Psychiatry Res 2008;162:256-261.

30. Huang H, Gundapuneedi T, Rao U. White matter disruptions in adolescents exposed to childhood maltreatment and vulnerability to psychopathology. Neuropsychopharmacology 2012; 37:2693-2701.

31. Choi J, Jeong B, Polcari A, Rohan ML, Teicher MH. Reduced fractional anisotropy in the visual limbic pathway of young adults witnessing domestic violence in childhood. Neuroimage 2012;59:1071-1079.

32. Teicher MH, Samson JA, Anderson CM, Ohashi K. The effects of childhood maltreatment on brain structure, function and connectivity. Nat Rev Neurosci 2016;17:652-666.

33. Asato MR, Terwilliger R, Woo J, Luna B. White matter deve/opment in adolescence: a DTI study. Cereb Cortex 2010; 20:2122-2131.

34. Simmonds DJ, Hallquist MN, Asato M, Luna B. Developmental stages and sex differences of white matter and behavioral development through adolescence: a longitudinal diffusion tensor imaging (DTI) study. Neuroimage 2014;92:356-368.

35. Andersen SL, Tomada A, Vincow ES, Valente E, Polcari A, Teicher MH. Preliminary evidence for sensitive periods in the effect of childhood sexual abuse on regional brain development. I Neuropsychiatry Clin Neurosci 2008;20:292-301.

36. Jeong B, Lee SW, Lee JS, Yoo JH, Kim KW, Cho S, et al. The psychometric properties of the Korean version of the verbal abuse questionnaire in university students. Psychiatry Investig 
2015;12:190-196.

37. Spielberger CD, Gorsouh RL. Manual for the state-trait anxiety inventory. Palo Alto, CA:Consulting Psychologists Press; 1970.

38. Beck AT, Ward CH, Mendelson M, Mock J, Erbaugh J. An inventory for measuring depression. Arch Gen Psychiatry 1961;4:561-571.

39. Lee SW, Yoo JH, Kim KW, Lee JS, Kim D, Park H, et al. Aberrant function of frontoamygdala circuits in adolescents with previous verbal abuse experiences. Neuropsychologia 2015;79:76-85.

40. Dale AM, Fischl B, Sereno MI. Cortical surface-based analysis. 1. Segmentation and surface reconstruction. Neuroimage 1999;9: 179-194.

41. Fischl B, Sereno MI, Dale AM. Cortical surface-based analysis. II: Inflation, flattening, and a surface-based coordinate system. Neuroimage 1999;9:195-207.

42. Fischl B, Sereno MI, Tootell RB, Dale AM. High-resolution intersubject averaging and a coordinate system for the cortical surface. Hum Brain Mapp 1999;8:272-284.

43. Fischl B, Dale AM. Measuring the thickness of the human cerebral cortex from magnetic resonance images. Proc Natl Acad Sci U S A 2000:97:11050-11055.

44. Ségonne F, Dale AM, Busa E, Glessner M, Salat D, Hahn HK, et al. A hybrid approach to the skull stripping problem in MRI. Neuroimage 2004;22:1060-1075.

45. Ennis DB, Kindlmann G. Orthogonal tensor invariants and the analysis of diffusion tensor magnetic resonance images. Magn Reson Med 2006; 55:136-146.

46. Smith SM, Jenkinson M, Johansen-Berg H, Rueckert D, Nichols TE, Mackay CE, et al. Tract-based spatial statistics: voxelwise analysis of multi-subject diffusion data. Neuroimage 2006; 31:1487-1505.

47. Suzuki M, Hagino $H$, Nohara S, Zhou SY, Kawasaki $Y$, Takahashi T, et al. Male-specific volume expansion of the human hippocampus during adolescence. Cereb Cortex 2005; 15:187-193.

48. Sapolsky RM. Glucocorticoids and hippocampal atrophy in neuropsychiatric disorders. Arch Gen Psychiatry 2000;57: 925-935.

49. McEwen BS. Stress and hippocampal plasticity. Annu Rev Neurosci 1999;22:105-122.

50. Ivy AS, Rex CS, Chen Y, Dubé C, Maras PM, Grigoriadis DE, et al. Hippocampal dysfunction and cognitive impairments provoked by chronic early-life stress involve excessive activation of CRH receptors. J NeurosCi 2010;30:13005-13015.

51. Stein MB, Koverola C, Hanna C, Torchia MG, McClarty B. Hippocampal volume in women victimized by childhood sexual abuse. Psychol Med 1997;27:951-959.

52. Burgess N, Maguire EA, O'Keefe J. The human hippocampus and spatial and episodic memory. Neuron 2002;35:625-641.

53. Gould E, Tanapat P. Stress and hippocampal neurogenesis. Biol Psychiatry 1999;46:1472-1479.

54. Kawakami R, Shinohara Y, Kato Y, Sugiyama H, Shigemoto R,
Ito I. Asymmetrical allocation of NMDA receptor epsilon2 subunits in hippocampal circuitry. Science 2003;300:990-994.

55. Shinohara $Y$, Hirase $H$, Watanabe $M$, Itakura $M$, Takahashi $M$, Shigemoto R. Left-right asymmetry of the hippocampal synapses with differential subunit allocation of g/utamate receptors. Proc Natl Acad Sci U S A 2008;105:19498-19503.

56. Kadar T, Dachir S, Shukitt-Hale B, Levy A. Sub-regional hippocampal vulnerability in various animal models leading to cognitive dysfunction. I Neural Transm (Vienna) 1998; 105:987-1004.

57. Bartsch T, Döhring J, Reuter S, Finke C, Rohr A, Brauer H, et al. Selective neuronal vulnerability of human hippocampal CA1 neurons: lesion evolution, temporal course, and pattern of hippocampal damage in diffusion-weighted MR imaging. I Cereb Blood Flow Metab 2015;35:1836-1845.

58. Schmidt-Kastner R, Freund TF. Selective vulnerability of the hippocampus in brain ischemia. Neuroscience 1991;40:599636.

59. Ouyang YB, Voloboueva LA, Xu LJ, Giffard RG. Selective dysfunction of hippocampal CA1 astrocytes contributes to delayed neuronal damage after transient forebrain ischemia. J Neurosci 2007;27:4253-4260.

60. Pawlak R, Rao BS, Melchor JP, Chattarji S, McEwen B, Strickland $\mathrm{S}$. Tissue plasminogen activator and plasminogen mediate stress-induced decline of neuronal and cognitive functions in the mouse hippocampus. Proc Natl Acad Sci U S A 2005;102:18201-18206.

61. Butler TR, Self RL, Smith KJ, Sharrett-Field LJ, Berry JN, Littleton JM, et al. Selective vulnerability of hippocampal cornu ammonis 1 pyramidal cells to excitotoxic insult is associated with the expression of polyamine-sensitive N-methyl-D-asparate-type g/utamate receptors. Neuroscience 2010; 165:525-534.

62. Joëls M. Stress, the hippocampus, and epilepsy. Epilepsia 2009;50:586-597.

63. Herman JP, Dolgas CM, Carlson SL. Ventral subiculum regulates hypothalamo-pituitary-adrenocortical and behavioural responses to cognitive stressors. Neuroscience 1998;86:449459.

64. Mueller NK, Dolgas CM, Herman JP. Stressor-selective role of the ventral subiculum in regulation of neuroendocrine stress responses. Endocrinology 2004; 145:3763-3768.

65. Herman JP. Regulation of adrenocorticosteroid receptor mRNA expression in the central nervous system. Cell Mol Neurobiol 1993;13:349-372.

66. Sarrieau A, Dussaillant M, Agid F, Philibert D, Agid Y, Rostene W. Autoradiographic localization of g/ucocorticosteroid and progesterone binding sites in the human post-mortem brain. J Steroid Biochem 1986;25:717-721.

67. Stumpf WE, Heiss C, Sar M, Duncan GE, Craver C. Dexamethasone and corticosterone receptor sites. Differential topographic distribution in rat hippocampus revealed by high resolution autoradiography. Histochemistry 1989;92:201-210. 
68. Reul JM, de Kloet ER. Two receptor systems for corticosterone in rat brain: microdistribution and differential occupation. Endocrinology 1985;117:2505-2511.

69. McEwen BS. The ever-changing brain: cellular and molecular mechanisms for the effects of stressful experiences. Dev Neurobiol 2012;72:878-890.

70. Smith MA, Makino S, Kvetnansky R, Post RM. Stress and g/ucocorticoids affect the expression of brain-derived neurotrophic factor and neurotrophin-3 mRNAs in the hippocampus. J Neurosci 1995; 15:1768-1777.

71. McEwen BS. The neurobiology of stress: from serendipity to clinical relevance. Brain Res 2000;886:172-189.

72. McEwen BS. Sex, stress and the hippocampus: allostasis, allostatic load and the aging process. Neurobiol Aging 2002;23: 921-939.

73. Wisse LE, Biessels GJ, Geerlings MI. A critical appraisal of the hippocampal subfield segmentation package in freesurfer. Front Aging Neurosci 2014;6:261.

74. Everaerd D, Gerritsen L, Rijpkema M, Frodl T, van Oostrom I, Franke B, et al. Sex modulates the interactive effect of the serotonin transporter gene polymorphism and childhood adversity on hippocampal volume. Neuropsychopharmacology 2012;37: 1848-1855.

75. Frodl T, Reinhold E, Koutsouleris N, Reiser M, Meisenzahl EM. Interaction of childhood stress with hippocampus and prefrontal cortex volume reduction in major depression. J Psychiatr Res 2010;44:799-807.

76. Bale TL. Lifetime stress experience: transgenerational epigenetics and germ cell programming. Dialogues Clin Neurosci 2014; 16:297-305.

77. Schmaal L, Veltman DJ, van Erp TG, Sämann PG, Frodl T, Jahanshad N, et al. Subcortical brain alterations in major depressive disorder: findings from the ENIGMA Major Depressive Disorder working group. Mol Psychiatry 2016; 21:806-812.

78. van Erp TG, Hibar DP, Rasmussen JM, Glahn DC, Pearlson GD, Andreassen OA, et al. Subcortical brain volume abnormalities in 2028 individuals with schizophrenia and 2540 healthy controls via the ENIGMA consortium. Mol Psychiatry 2016;21:585.

79. Gilbertson MW, Shenton ME, Ciszewski A, Kasai K, Lasko NB, Orr SP, et al. Smaller hippocampal volume predicts pathologic vulnerability to psychological trauma. Nat Neurosci 2002;5: 1242-1247.

80. Luders $\mathrm{E}$, Thompson PM, Toga AW. The development of the corpus callosum in the healthy human brain. I Neurosci 2010;30:10985-10990.

81. Qiu D, Tan LH, Zhou K, Khong PL. Diffusion tensor imaging of normal white matter maturation from late childhood to young adulthood: voxe/-wise evaluation of mean diffusivity, fractional anisotropy, radial and axial diffusivities, and correlation with reading development. Neuroimage 2008;41:223232.

82. Snook L, Plewes C, Beaulieu C. Voxe/ based versus region of interest analysis in diffusion tensor imaging of neurodevelopment. Neuroimage 2007;34:243-252.

83. Lebel C, Beaulieu C. Longitudinal development of human brain wiring continues from childhood into adulthood. I Neurosci 2011;31:10937-10947.

84. Teicher MH, Dumont NL, Ito Y, Vaituzis C, Giedd JN, Andersen SL. Childhood neglect is associated with reduced corpus callosum area. Biol Psychiatry 2004;56:80-85.

85. Raybaud C. The corpus callosum, the other great forebrain commissures, and the septum pellucidum: anatomy, development, and malformation. Neuroradiology 2010;52:447-477.

86. Gloor P, Salanova V, Olivier A, Quesney LF. The human dorsal hippocampal commissure. An anatomically identifiable and functional pathway. Brain 1993;116(Pt 5):1249-1273.

87. Paul LK, Brown WS, Adolphs R, Tyszka JM, Richards LJ, Mukherjee P, et al. Agenesis of the corpus callosum: genetic, developmental and functional aspects of connectivity. Nat Rev Neurosci 2007;8:287-299.

88. Livy DJ, Wahlsten D. Retarded formation of the hippocampal commissure in embryos from mouse strains lacking a corpus callosum. Hippocampus 1997;7:2-14.

89. Teipel SJ, Bayer W, Alexander GE, Bokde AL, Zebuhr Y, Teichberg D, et al. Regional pattern of hippocampus and corpus callosum atrophy in Alzheimer's disease in relation to dementia severity: evidence for early neocortical degeneration. Neurobiol Aging 2003;24:85-94.

90. Villain N, Desgranges B, Viader F, de la Sayette V, Mézenge F, Landeau B, et al. Relationships between hippocampal atrophy, white matter disruption, and gray matter hypometabolism in Alzheimer's disease. J Neurosci 2008;28: 6174-6181.

91. Teicher $\mathrm{MH}$, Parigger A. The 'Maltreatment and Abuse Chronology of Exposure' (MACE) scale for the retrospective assessment of abuse and neglect during development. PLoS One 2015;10:e0117423.

92. Banny AM, Cicchetti D, Rogosch FA, Oshri A, Crick NR. Vulnerability to depression: a moderated mediation model of the roles of child maltreatment, peer victimization, and serotonin transporter linked polymorphic region genetic variation among children from low socioeconomic status backgrounds. Dev Psychopathol 2013;25:599-614.

93. Tomoda A, Sheu YS, Rabi K, Suzuki H, Navalta CP, Polcari A, et al. Exposure to parental verbal abuse is associated with increased gray matter volume in superior temporal gyrus. Neuroimage 2011;54 Supp/ 1:S280-S286. 